\title{
SURVEY OF NUTRITIONAL STATUS AND HEALTH BEHAVIOR OF PREGNANT WOMEN IN BONTOMATE'NE HEALTH CENTER OF JENEPONTO DISTRICT, INDONESIA
}

\section{Yusriani* $^{*}$}

Faculty of Public Health, Indonesian Moslem University, Indonesia

Accepted: 24 May 2016

\section{*Correspondence:}

Yusriani

Faculty of Public Health, Indonesian Moslem University, Indonesia

Email :yusriani83@rocketmail.com

Copyright: (C) the author(s), YCAB publisher and Public Health of Indonesia. This is an open-access article distributed under the terms of the Creative Commons Attribution Non-Commercial License, which permits unrestricted non-commercial use, distribution, and reproduction in any medium, provided the original work is properly cited.

\begin{abstract}
Background: Maternal mortality is a global health problem, and generally occurs mainly in developing countries. The main causes of maternal mortality still include bleeding, eclampsia and infections which contribute about $60 \%$ of total maternal deaths. Interventions to reduce the number of maternal deaths is pretty much done, especially in improving the nutritional status and health behavior of pregnant women, but have not yielded optimal results.

Aim: This study aimed to determine the nutritional status and health behavior of pregnant women at health centers Bontomate'ne Jeneponto.

Methods: This study uses survey design analytic descriptive approach. The population was all pregnant women in the working area Bontomate'ne health center with 189 people. All the population census or taken by total sampling. Data obtained through direct interviews and observations by using a questionnaire.

Results: The results showed that normal nutritional status of pregnant women as much as $85.1 \%$ and maternal nutritional status category KEK as much as $14.9 \%$. Knowledge of pregnant women about the risk factors of maternal death, danger signs of pregnancy, the importance of antenatal care (ANC), planning a pregnancy and a safe delivery and post natal care (PNC) is categorized as less as much as 90.1\%, and the mother's knowledge enough category only $9.9 \%$. Pregnant women who have a positive attitude by $71.3 \%$ and amounted to $28.7 \%$ negative. Actions poor pregnant women as much as $34.7 \%$ and the capital measures both categories as much as $65.3 \%$.

Conclusion: Nutritional status and health behavior of pregnant mothers can provide chances for the occurrence of maternal deaths. Suggested the need to conduct needs to conduct education and training to build the knowledge and experience of pregnant women about the nutritional status and health behavior was good with involving the active participation of health workers, community, family, mother and husband.
\end{abstract}

Key Words : Nutritional Status, Health Behavior, Pregnancy 


\section{INTRODUCTION}

Maternal mortality is a global health problem, and generally occurs mainly in developing countries. Global agreement known as the Millennium Development Goals (MDGs), particularly goals to 5 aims to reduce the three-quarters Maternal Mortality Ratio (MMR) in 2015 - with a base in $1990 .^{1}$ Some countries have managed to achieve the target of MMR, and several other countries, including Indonesia, despite the drop, the MDG 5 in 2015 is not achieved. Compared to other countries in the ASEAN region, MMR in Indonesia is higher than Thailand, Myanmar, Malaysia, the Philippines, although still lower than Camboja and Laos. $^{2}$

Based on the Indonesian Demographic and Health Survey (IDHS) of 2012 showed a very alarming maternal mortality rate increased from $228 / 100,000$ live births in 2007 was 359 per 100 thousand live births. It means that in one hour, three to four mothers in Indonesia died in childbirth. The day there are 72 to 96 maternal deaths, 2,160 to 5,760 a month and a year 25,000 to 34560 mothers die in childbirth. More than war deaths from Vietnam are 20 thousands of people.

WHO report on the causes of maternal death obtained information that the main causes of maternal mortality still include bleeding, eclampsia and infections. $^{3,4}$ The three main causes that contribute approximately $60 \%$ of total maternal deaths. The same pattern also occurred in Indonesia. Although it has been known major cause of maternal mortality, but it is still rarely performed an analysis of the causes of death for a certain period of time. This information is important because if there is a significant change should be a change in the intervention MMR decline.

Based on the results of the evaluation obtained information that generally causes of high maternal mortality is handling three late is too late to bring to the health facilities, late diagnosis and delayed treatment or refer in health facilities. The three main causes of delayed partly because the clinical problem with the number of cases of such bleeding $(20.4 \%)$, eclampsia $(16.2 \%)$, hypertension $(9.2 \%)$ and abortion (4.1\%). Other causes for healthcare facilities shown in the lack of adequate for home delivery (63.2\%) and the lack of medical personnel and non home health care facilities. In addition, the difficulty of access to the region so that visit pregnancy, pregnancy help, and postpartum visits are not running, particularly in isolated areas. Then the problems of administration and human resources such as low capacity health workers, lack of training, lack of support facility, salaries are often delayed or rapel six months, inadequate incentives, security issues, and so forth. In addition, nonmedical causes, such as cultural like not want to be examined male medical personnel, factors such as a more traditional elders believe go to traditional healers, education levels, costs, knowledge, absence of local government intend to address this issue and others exacerbating the situation. ${ }^{4,5,6}$

In Indonesia, there are variations MMR between provinces. South Sulawesi province in 2013 had a population of 8 million people spread in 21 districts and 3 cities and annually reported to be between 80-140 people pregnant women who died from pregnancy or childbirth. ${ }^{7}$ The results of the study shows that over the past six years, the maternal mortality rate below 100 per 100,000 live births. Despite a downturn, in 2012 there was an increase MMR compared to the previous three years with the number of maternal deaths to 160 people, or 110.26 per 100,000 live births, pregnant maternal mortality is 
composed of 45 people (28.1\%), childbirth maternal mortality 60 people $(40 \%)$, postpartum maternal deaths 55 people (30\%). In 2013 again occurred a sharp decline compared to the year 2012 with the number of 115 people or 78.38 deaths per 100,000 live births, consisting of $15.65 \%$ of pregnant maternal deaths, childbirth maternal mortality $51.30 \%, \quad 33.04 \%$ postpartum maternal deaths. ${ }^{8}$

Trend maternal mortality rate in Jeneponto increased from the year 2011 as many as three people (46 per $100,000 \mathrm{KH}$ ) to $11(170$ per $100,000 \mathrm{KH})$ in 2012 . Then there was a decline in 2013 as many as five people (82 per $100,000 \mathrm{KH})$, and experienced a sharp increase in 2014 as many as 13 people dead mother. 2013. Coverage K1 amounted to $97.6 \%$ increase to $97.85 \%$ in 2014 , and coverage K4 decreased from $89.8 \%$ to $84.69 \%$, if compared by indicator targets coverage K4 nationally was still below the target minimum service standards (SPM) is $95 \%$. The percentage of births attended skilled health personnel (coverage $\mathrm{Pn}$ ) is very alarming that in 2013 only reached $85.6 \%$ and increased to $86.65 \%$, the remaining maternity shaman When compared to the national target of minimum service standards (SPM) $90 \%$ is not reached. Based on data from the death of PHC Bululoe recorded maternal mortality 1 which are due to bleeding, the number of live births born as many as 192 people dead and as many as 2 people. $^{9}$

The determinant of maternal mortality is also influenced by the nutritional status and health behaviors. Maternal nutritional status can be measured by body height, body mass index (BMI) prepregnancy, weight gain during pregnancy, and hemoglobin $(\mathrm{Hb})$ mother. ${ }^{10,11}$ Health Behavioral ie matters relating to actions or activities of a person in maintaining and improving health. Including measures to prevent diseases, personal hygiene, choosing food, sanitation and so forth. ${ }^{12}$ LILA of measurements in pregnant women associated with chronic energy deficiency (CED). KEK is a problem that often occurs in pregnant women. LILA $<23.5 \mathrm{~cm}$ should get treatment to avoid complications in the fetus. Malnutrition in pregnant women can cause a risk and maternal complications, such as anemia, bleeding and maternal weight does not grow normally and infectious diseases. Mothers who experience KEK will be more at risk of having low birth weight. ${ }^{11,13}$

Based on the results of Health Research (Riskesdas 2013) in Jeneponto percentage of low birth weight by 16 percent, 40.9 percent short children, child malnutrition 25.6 percent and child over nutrition 1.7 percent. Maternal conditions no better where pregnant women are chronic energy deficiency of $32.4 \%$, Aged Women Less Fertile Chronic Energy by $24 \%$. Fe intake was 90 Tablet only reached $24,3 \%{ }^{14}$

Based on data from ANC (Antenatal Care) at the Health Center Bontomatene number of maternity as many as 362 people. Mothers who have the book $\mathrm{MCH}$ (Maternal and Child Health) as much as $74.3 \%$, K1 coverage as much as $103.59 \%, 70.72 \%$ K4 coverage, the number Pregnant women who get a tablet Fe 1 as much as $103.59 \%$, the number Pregnant women who get a tablet Fe 3 as much as $70.72 \%$, the detection of high risk by health workers amounted to $29.17 \%$, the referral of cases of high risk of $34.09 \%$ Maternal and Neonatal high risk of $0.00 \%$. Integrated ANC Data on PHC Bontomate'ne pregnant women who examined her $\mathrm{Hb}$ as many as 45 people, anemia (8-11 $\mathrm{mg} / \mathrm{dl}$ ) as many as 24 people, anemia $(<8 \mathrm{mg} / \mathrm{dl})$ for 2 people. Examination of chronic energy deficiency (CED), pregnant women who have MUAC $<23.5 \mathrm{~cm}$ as many as 34 people. Total class 
Maternal formed three classes and midwife numbers of pregnant women carry the class as much as 3 midwives.

Data Delivery and Postpartum in Puskesmas Bontomate'ne target number of maternal/postpartum mothers as many as 364 people. Deliveries take health workers (PN) of which the total amount of $94.52 \%$ PN, PN in facilities of heath care $70.81 \%$, Non facilities of heath care PN at $1.73 \%$. Births in favor by as much as $2.60 \%$ Nonhealth workers, maternal handled Compilation (PK) $62.50 \%$, which is getting Vit A Ruling as much as $94.51 \%$, which carry out visits Ruling (KF) KF is 1 (6 hours- 3 days) as much as $68.5 \%$, KF 2 (4 days-28 days) of $64.2 \%$ and a KF 3 (29 days-42 days) $87.6 \% .^{14}$

Based on the description above, the researchers were interested in doing research on Nutritional Status Survey and Maternal Health Behaviour in Bontomate'ne Health Center Jeneponto District 2015.

\section{METHODS}

\section{Design, Population and Sample Research}

This research is a survey research with a descriptive approach that is viewed nutritional status, knowledge, attitude and practice of pregnant women includes a risk factor for maternal death, danger signs of pregnancy, the importance of the ANC, planning a pregnancy and a safe delivery and Post Natal Care (PNC). The population was all pregnant women in $\mathrm{PHC}$ of Bontomate'ne Turatea sub-district Jeneponto district of as many as 189 people. No samples were taken in this study, because all of the population is taken as respondents.

\section{Data Collection and Analysis}

The primary data obtained from interviews with respondents using questionnaire instrument. Data obtained from the Health Department Jeneponto in the year 2015. Data analysis was performed on the variables of the study, based on the goal is to produce a distribution and percentage of each variable.

\section{RESULTS}

This research was conducted in the working area of PHC Bontomate'ne Jeneponto Based on the results of the data processing has been done then systematically presented as follows: Table 1 shows that majority of pregnant women have a lifespan of 20-35 years (77.2\%), and which has aged $<20$ years $(9 \%),>35$ years $(13.8 \%)$. The majority of pregnant women in labor last have a lifespan of 2035 years $(48.7 \%)$, and which has aged $<20$ years $(9.5 \%),>35$ years $(3.2 \%)$. Mothers who are pregnant for the first time as much as $38.6 \%$. The majority of pregnant women age of first marriage is $67.2 \% \quad(20-35$ years), and which has aged $<20$ years $(32.8 \%)$. The majority of the number of the mother's pregnancy is $2-3$ at $45 \%$, the first pregnancy and $39.2 \%$ who experienced pregnancy $>3$ amounted to $15.9 \%$. The majority of the number of parity mother is primipara of $28 \%$, the first pregnancy and $39.7 \%$ who experienced pregnancy $>3$ amounted to $5.3 \%$. Women who have had abortions are at $9.5 \%$ Mothers who have a pregnancy spacing $<2$ years amounted to $11.1 \%$, and $>2$ years at $50.3 \%$.

Table 2 shows that pregnant women are mostly from villages Paitana $(40.2 \%)$, and Bontomate'ne $(23.3 \%)$. While originating from the village Bungungloe only $(2.1 \%)$ and the village Kayuloe East $(2.6 \%)$. Work aside housewife mother is self-employed (1.6\%), agricultural laborers $(3.1 \%)$, teachers' salaries $(1.1 \%)$ and civil servants $(0.5 \%)$, and that did not work while pregnant $(93.7 \%)$. The majority of maternal education level is elementary school (61.9\%) and junior (14.3\%), which was only completed high school $(12.2 \%)$ and there are still pregnant women who have never attended school $(4.8 \%)$. The 
majority of the husband's mother education level is elementary school $(60.3 \%)$ and junior (13.2\%), who completed high school $(15.3 \%)$ and still have a husband who never attended school (5.8\%). The majority of family income level $<\mathrm{UMP}$ is $<2,000,000(91.5 \%)$ and only $8.5 \%$ have incomes $>2,000,000$.

Table 1. Characteristics of Biological Pregnancy

\begin{tabular}{|c|c|c|}
\hline Characteristics of Biological Pregnancy & $(n=189)$ & $(\%)$ \\
\hline \multicolumn{3}{|l|}{ Age Group } \\
\hline$<20$ & 17 & 9.0 \\
\hline $20-35$ & 146 & 77.2 \\
\hline$>35$ & 26 & 13.8 \\
\hline \multicolumn{3}{|c|}{ Age Group Capital Current Newsletter Delivery } \\
\hline$<20$ & 18 & 9.5 \\
\hline $20-35$ & 92 & 48.5 \\
\hline$>35$ & 6 & 3.2 \\
\hline Kehamilan Pertama & 73 & 38.6 \\
\hline \multicolumn{3}{|l|}{ Age Mothers At First Married } \\
\hline$<20$ & 62 & 32.8 \\
\hline $20-35$ & 127 & 67.2 \\
\hline$>35$ & 0 & 0 \\
\hline \multicolumn{3}{|l|}{ Gravida } \\
\hline Primigravida & 74 & 39.2 \\
\hline $2-3$ & 85 & 45.0 \\
\hline$>3$ & 30 & 15.9 \\
\hline \multicolumn{3}{|l|}{ Parity } \\
\hline Nullipara & 75 & 39.7 \\
\hline Primipara & 53 & 28.0 \\
\hline $2-3$ & 51 & 27.0 \\
\hline$>3$ & 10 & 5.3 \\
\hline \multicolumn{3}{|l|}{ Ever Abortion } \\
\hline Yes & 18 & 9.5 \\
\hline No & 171 & 90.5 \\
\hline \multicolumn{3}{|l|}{ Distance Pregnancy } \\
\hline$<2$ yar & 21 & 11.1 \\
\hline$\geq 2$ year & 95 & 50.3 \\
\hline The first pregnancy & 73 & 38.6 \\
\hline
\end{tabular}

Table 2. Characteristics Geographic and Social Pregnancy

\begin{tabular}{|l|c|c|}
\hline Characteristics Geographic and Social Pregnancy & $(\mathbf{n}=\mathbf{1 8 9})$ & $\mathbf{( \% )}$ \\
\hline From the village of Pregnancy & 44 & 23.3 \\
\hline Bontomate'ne & 4 & 2.1 \\
Bungungloe & 20 & 10.6 \\
Kayuloe Barat & 5 & 2.6 \\
Kayuloe Timur & 27 & 14.3 \\
Langkura & 76 & 40.2 \\
Paitana & 13 & 6.9 \\
Parasangang Beru & & \\
\hline
\end{tabular}




\begin{tabular}{|l|c|c|}
\hline Type of work & 3 & 1.6 \\
Entrepreneur & 6 & 3.1 \\
Farm workers & 2 & 1.1 \\
Teacher Honor & 1 & 0.5 \\
PNS & 177 & 93.7 \\
IRT & 9 & 4.8 \\
Pregnancy Education Level & 117 & 61.9 \\
\hline Never Schools & 27 & 14.3 \\
Elementary School / equivalent & 23 & 12.2 \\
Junior High School/ Equal & 13 & 6.9 \\
Senior Haigh School / Equal & \multicolumn{2}{|l|}{} \\
University/College & 11 & 5.8 \\
Husband Pregnant Women Education Level & 114 & 60.3 \\
\hline Never Schools & 25 & 13.2 \\
Elementary School / equivalent & 29 & 15.3 \\
Junior High School/ Equal & 10 & 5.3 \\
Senior Haigh School / Equal & 173 & \\
University/College & 16 & 81.5 \\
\hline Family Income Levels & \multicolumn{2}{|l}{} \\
\hline <2.000.000 & \multicolumn{2}{|l}{} \\
\hline 2.000.000 &
\end{tabular}

Table 3 shows that pregnant women who experience KEK (MUAC $<23.5 \mathrm{~cm}$ ) amounted to $13.8 \%$, and the nutritional status of pregnant women were normal at $86.2 \%$. The majority of knowledge of pregnant women about the risk factors of maternal death, danger signs of pregnancy, the importance of antenatal care (ANC), planning a pregnancy and a safe delivery and post natal care (PNC) in the category of less that is equal to $85.7 \%$, and were knowledgeable enough to just $14.3 \%$. The majority of pregnant women in the category positive attitude in the amount of $70.9 \%$, and that has a negative attitude amounted to $29.1 \%$. The majority of the practice of pregnant women to the risk factors of maternal death, danger signs of pregnancy, the importance of antenatal care (ANC), planning a pregnancy and a safe delivery and post natal care (PNC) in the category of good that is equal to $50.8 \%$, and which have the practice is not good for $49.2 \%$.

Table 4 shows that the 162 respondents whose knowledge is less,
$42.6 \%$ had action is less good and $57.4 \%$ good. The 27 respondents whose knowledge is sufficient, $88.9 \%$ had action is less good and $11.1 \%$ good. The 55 respondents who have a negative attitude, $43.6 \%$ had less action is good and $56.4 \%$ good. The 134 respondents who have a positive attitude, $51.5 \%$ had action is less good and $48.5 \%$ good. Results of Yates Correction of test showed that there was significant relationship between knowledge and action of pregnant women $(\mathrm{p}=0.000$ $<\alpha 0.05$ ), and there was no significant relationship between attitude and action of pregnant women $(p=0412>\alpha 0.05)$.

Table 5 shows that the 162 respondents whose knowledge is less, $49 \%$ have a negative attitude and a positive $69.8 \%$. The 27 respondents whose knowledge is sufficient, $22.2 \%$ had a negative attitude and a positive $77.8 \%$. Results of Yates Correction test showed that the value of $p=0535>\alpha 0.05$, so there is no significant relationship between knowledge and attitude of pregnant women. 
Tabel 3. Variable distribution Examined

\begin{tabular}{|l|c|c|}
\hline Variable & (n=189) & (\%) \\
\hline Nutritional Status & 26 & 13.8 \\
\hline KEK & 163 & 86.2 \\
Normal & 162 & 85.7 \\
\hline Category Knowledge & 27 & 14.3 \\
\hline Less & \multicolumn{2}{|l|}{} \\
Enough & 55 & 29.1 \\
\hline Category attitude & 134 & 70.9 \\
\hline Negative & 93 & 49.2 \\
Positive & 96 & 50.8 \\
\hline Category Practice & 96 \\
\hline Not Good & \multicolumn{2}{|l|}{} \\
Good
\end{tabular}

Table 4. Analysis of Relationship between Variables (Yates Correction Test)

\begin{tabular}{|c|c|c|c|c|c|c|c|}
\hline \multirow{3}{*}{ Variabele } & \multicolumn{4}{|c|}{ Practice } & \multirow{2}{*}{\multicolumn{2}{|c|}{ Total }} & \multirow{3}{*}{$P$ value } \\
\hline & \multicolumn{2}{|c|}{ Not Good } & \multicolumn{2}{|c|}{ Good } & & & \\
\hline & $\mathrm{N}$ & $\%$ & $\mathrm{n}$ & $\%$ & $\mathrm{~N}$ & $\%$ & \\
\hline \multicolumn{7}{|c|}{ Knowledge } & \multirow{3}{*}{$0.000 *$} \\
\hline Less & 69 & 42.6 & 93 & 57.4 & 162 & 100 & \\
\hline Enough & 24 & 88.9 & 3 & 11.1 & 27 & 100 & \\
\hline \multicolumn{7}{|l|}{ Attitude } & \\
\hline Negative & 24 & 43.6 & 31 & 56.4 & 55 & 24 & 0,412 \\
\hline Positive & 69 & 51.5 & 65 & 48.5 & 134 & 69 & \\
\hline
\end{tabular}

Table 5. Analysis of Relationship between Variables (Fisher Exact Test)

\begin{tabular}{|l|c|c|c|c|c|c|c|}
\hline \multirow{2}{*}{ Variabel } & \multicolumn{4}{|c|}{ Attitude } & \multicolumn{2}{|c|}{ Total } & \multirow{2}{*}{ P Value } \\
\cline { 2 - 6 } & \multicolumn{2}{|c|}{ Negative } & \multicolumn{2}{|c|}{ Positive } & \multicolumn{2}{|c|}{} \\
\cline { 2 - 6 } Knowledge & $\mathrm{N}$ & $\%$ & $\mathrm{~N}$ & $\%$ & $\mathrm{~N}$ & $\%$ & \multirow{2}{*}{0.535} \\
\hline Less & & & & & & & \\
\hline Enough & 49 & 30.2 & 113 & 69.8 & 162 & 100 & \\
\hline
\end{tabular}

\section{DISCUSSIONS}

\section{Nutritional Status}

MUAC of measurements in pregnant women associated with chronic energy deficiency (CED). KEK is a problem that often occurs in pregnant women. MUAC $<23.5 \mathrm{~cm}$ should get treatment to avoid complications in the fetus. Malnutrition in pregnant women can cause a risk and maternal complications, such as anemia, bleeding and maternal weight does not grow normally and infectious diseases. Mothers who experience KEK will be more at risk of having low birth weight. ${ }^{11,13}$

The nutritional status of a person is merely the result of a balance between the consumption of nutrients with the needs of the person. The nutritional status of pregnant women affect fetal growth being 
conceived. When the normal nutritional status of mothers during pregnancy, more likely to give birth to a healthy baby, just a month with normal weight. In other words, the quality of babies born very dependent on the state of maternal nutrition during pregnancy. ${ }^{11,13,15}$

The results showed that the nutritional status of pregnant women of normal category 163 people $(86.2 \%)$ and maternal nutritional status category KEK as many as 26 people (13.8\%). The period of pregnant women is a period where a person women need different nutrients that far more than necessary in the nonpregnant state. It is known that a fetus requires nutrients and only a mother can give. Thus foods pregnant women should be quite nutritious so that the fetus acquire enough nutritious food. The mother's diet during pregnancy and the nutritional state of the mother during pregnancy is closely linked to low birth weight (LBW). If the food consumed by the mother less and maternal nutritional status ugly it is likely that babies are born with low birth weight $^{11,13}$. Pregnancy is a physiological process that can happen to any woman. Expected outcomes of pregnancy is the birth of a healthy baby then grow flowers optimally and healthy mother anyway. ${ }^{15}$

An adult woman who is not pregnant, nutritional purposes is used for routine activities in the metabolism of the body, physical activity, and maintaining a balance of all processes in the body. Whereas in adult women who are pregnant, in addition to the routine processes that are also needed extra energy and nutrients for the formation of new tissue, is the fetus, placenta, uterus and mammary gland. ${ }^{16}$

Pregnant women are encouraged to eat enough, is varied so that the need for a variety of nutrients can be met. An increasing need to support the preparation of the future baby is born. How overeating should be avoided, as it may harm himself.
However the addition of nutrients to be tailored to the needs.

The results also showed that in addition to the nutritional status of mothers KEK there are also other risk factors that may endanger the pregnancy, childbirth and postpartum, covers there are pregnant women who have aged $<20$ years $(9 \%)$ and $>35$ years $(13.8 \%)$, there are Last pregnant women in labor had aged $<20$ years $(9.5 \%),>35$ years $(3.2 \%)$. There are pregnant women who first married aged $<20$ years $(32.8 \%)$, and no one has aged $>35$ years, there are $6.3 \%$ of women who worked as a laborer, teacher salaries, civil servants and self-employed. The majority of maternal education level is elementary school (61.9\%), The majority of elementary education husband of $60.3 \%$. The majority of family income level $<$ UMP is $<2,000,000$ (91.5\%), pregnant women first pregnancy and $39.2 \%$ who experienced pregnancy $>3$ amounted to $15.9 \%$. Primiparous pregnant women at $28 \%$, the first pregnancy and $39.7 \%$ who experienced pregnancy $>3$ amounted to $5.3 \%$. Women who have had abortions are at $9.5 \%$, and the mother who had gestational distance $<2$ years amounted to $11.1 \%$. The more types of risk factors that are owned by the mother, the greater the chance of experiencing maternal mortality.

\section{Knowledge}

Maternal mortality in Indonesia is quite high at 395 per 100,000 births for the area and in the corners. The main cause is due to lack of information and knowledge of nutrition and maternal health during pregnancy. One of the effects of lack of knowledge of nutrition and maternal health. $^{2}$

The results showed that the knowledge of pregnant women about the risk factors of maternal death, danger signs of pregnancy, the importance of antenatal care (ANC), planning a pregnancy and a 
safe delivery and post natal care (PNC) entered enough only $9.9 \%$. Knowledge is very important to the formation of a behavior. Knowledge of the danger signs in pregnancy greatly helps reduce AKI, because by knowing the danger signs in pregnancy an expectant mother will be faster seek health services so that the risk of pregnancy will be detected and handled early. From experience and research behavior based knowledge turned out to be more lasting than the behavior that is not based on knowledge. ${ }^{12}$

Lack of knowledge of mothers due to the mother's educational level is low where the majority of pregnant women educated elementary school as much as $61.9 \%$, and who never went to school 4.8\%. Pregnant women are very important to know the danger signs in pregnancy to minimize the maternal mortality rate. Where the results showed only $10.9 \%$ of women who answered correctly about the danger signs in pregnancy that is bleeding from the birth canal, swelling in the feet, hands, or face accompanied by headache or seizures, fever or high heat, premature rupture of membranes, the baby in the womb movement is reduced or not moving and excessive nausea and vomiting (Hyperemesis Gravidarum).

This study is in line with Budiman (2014) which says that Of the 55 pregnant women in rural Kertajaya Tanggeung District of Cianjur Regency acquired the knowledge level of pregnant women less category as many as 29 people $(52.7 \%)$ and 26 pregnant women $(47.3 \%)$ have a sufficient level of knowledge. ${ }^{17}$

Knowledge is something that is needed in order to change the mindset and behavior of groups and communities. According Notoadmodjo (2007), knowledge is the result of out and this happens after a person perform sensing on a specific object. ${ }^{12}$
The results also showed that the majority of pregnant women do not know the terms of the ANC (77.8\%) and did not know the frequency of antenatal care visits (79.4\%). Mothers who know that pregnant women should stay at home if he suffers from severe headaches by $19 \%$, mothers who know about the ANC goal of $8.9 \%$. Mothers who know about the ANC standard of $13.2 \%$. Mothers who know how to maintain and care for the pregnancy of $67.7 \%$. Mothers who know how to plan delivery amounting to $22.89 \%$. Mothers who know the signs of labor at $24.3 \%$. Mothers who know about the meaning and purpose of inspection, maintenance and post-natal services by $55 \%$. Mothers who know about the stages of postnatal care is only $9 \%$.

According Notoatmodjo (2007), if desired an institutionalized behavior or sustainable then treated their knowledge and belief / attitude positive about what will be done. Someone who obtained outside stimuli will arise the process of introducing something. This will generate cognitive factors (knowledge) of the person. $^{12}$

The results are consistent with the theory L.Green (1991), that the knowledge of a person is one of the factors (predisposing) to facilitate someone special act and behave, in line with Notoatmodjo (2005), which states that when the acceptance of new behavior or adoption behavior based on knowledge will be more sustainable (long lasting), and if the behavior is not based on knowledge not will take place lasting. ${ }^{12}$

Based on the above theory, the need for communication, information and education that is sustainable as counseling at any time posyandu and enable mothers classes in order to enhance the knowledge of mothers about pregnancy and safe delivery. Materials needed especially about how many times should consult pregnancy, 
age is safe for pregnant and give birth, who should birth attendants mother, danger signs in pregnancy and childbirth, to whom should consult when encountered danger signs in pregnancy, distance safe delivery, and how many times should consult the health professionals during pregnancy. Should pregnant women already know and understand the goodness of prenatal care or who should be attending births positive thoughts will arise. This thinking will generate a positive attitude that is agreed in the case of pregnant women and further intend to pregnancy or childbirth in a safe and healthy for mother and baby.

\section{Attitude}

Attitude clearly shows their suitability connotation reaction to certain stimuli in everyday life is an emotional reaction to the social stimulus. Attitude is not an action or activity, but predisposes the action of a behavior. ${ }^{12}$

The results showed that maternal attitudes positive categories were 134 people $(70.9 \%)$ while the negative attitude of pregnant women category many as 55 people $(29.1 \%)$. Factors that influence the formation of attitudes among other personal experiences, culture, others that are considered important and the mass media, In this study, the high percentage of positive attitude of pregnant women in because of the presumption that the mother needs to set the distance pregnancy join $\mathrm{KB}$ program as much as $56.4 \%$ who said they agree, and statements agree with taking tablets to maternal anemia fe as much as $83.2 \%$, and the average family is already preparing for the delivery fees to await the birth of her baby.

Referring to the statement Notoatmodjo (2007) attitude is inseparable from the family socialization, education, school or outside the school as well as knowledge in the community. The role of education can not be ignored, because education is done almost for life, either through formal or informal education. ${ }^{12}$

A positive attitude towards health values do not always materialize in a real action. This is caused by the attitude will be manifested in an action depending on the current situation, the attitude will be followed or by the action, which refers to the experiences of others or based on a lot or a little experience, and values prevailing in a society that becomes a handle everyone. $^{12}$

\section{Practice}

An understanding of the guidelines for Maternal and Child Health (MCH), especially antenatal visits is still lacking, so it is still found pregnant women who do not know the importance of prenatal care on a regular basis. Antenatal visit is one form of behavior. According to Lawrence Green, factors relating to those last three are: predisposing factors, enabling factors, and reinforcing factors. Which included predisposing factors are: knowledge, attitudes, beliefs, traditions, and values. $18,19,20,21$

The results showed that the maternal action unfavorable category as many as 93 people (49.2\%) and the mother acts both categories as many as 96 people $(50.8 \%)$. A high percentage of pregnant women less action either because there are still many women who do not carry out the measurement of height, blood pressure, MUAC measurements, abdominal examination thus affecting follow-mother. For it takes the role of health workers and family participation to support pregnant women to carry out the medical examination.

Behavior that is not good, due to the $42.6 \%$ of women had less knowledge, and $43.6 \%$ who have a negative attitude. While including the Knowledge and Attitudes Relations Pregnant Women to Conduct Inspection Visits supporting 
factor is the availability of health facilities, and the latter of which includes a driving factor is the attitude and behavior of health workers. In theory it is changes in behavior or adopt new behaviors that follow the stages, through a process of change: knowledge, attitude, practice. $^{21}$

The results showed that the type of service that pregnant women get when antenatal namely: Weigh Weight and Measure height (48.1\%), Measuring blood pressure (52.4\%), Assessing the nutritional status (measuring LILA) $(45 \%)$, Checking the stomach ( TFU) (49.7\%), Injecting TT (48.1\%), Giving iron tablet (45\%), test PMS (11.6\%), Gathering of speech (16.4\%), Determine presentation pulse and heart rate pulse (DJJ) $(51.9 \%)$ and case management only $(5.3 \%)$. Health workers, particularly midwives must have extensive knowledge, high motivation, are required to use the capabilities in various aspects of life, especially in providing services to patients, and thus be able of giving a positive impact in accordance with its science. But the implementation of antenatal care encounter a number of obstacles, caused by lack of knowledge midwife about ante-natal services. Theoretically, action is given by health personnel (midwives) during antenatal care will very much affect the health of the mother and fetus because in a complete examination will easily download the detection of abnormalities that may occur during pregnancy or before birth. ${ }^{22}$

Complications of labor is an obstetric emergencies most likely to cause maternal mortality. Many things can cause birth complications that poor maternal health, reproductive health status, access to health services, as well as the behavior of poor health of the mother's own. ${ }^{23}$

The results showed that $45 \%$ mother, husband and family are planning a pregnancy, 69.8\% Capital saving for the cost of labor, $67.7 \%$ Capital in preparation for labor/delivery, only $29.6 \%$ Capital prepare prospective blood donors, $77.2 \%$ Capital set up transportation to childbirth so as to minimize the risk of maternal death.

In addition the incidence of birth complications can be influenced also by the status of women in the family and community and family status in society. The results showed that the risk of the incidence of birth complications in women giving birth ANC irregular, where antenatal $<4$ times during pregnancy and do not meet the service 5T, a risk 2,588 times more likely to develop complications birth than women who did antenatal care (ANC) regularly or $\geq 4$ times during pregnancy and meet the service " $5 \mathrm{~T}$ ". ${ }^{23}$

\section{CONCLUSION}

The nutritional status of pregnant women as much as $86.2 \%$ of normal category and maternal nutritional status category KEK as much as $13.8 \%$. Knowledge of pregnant women about the risk factors of maternal death, danger signs of pregnancy, the importance of antenatal care (ANC), planning a pregnancy and a safe delivery and post natal care (PNC) is categorized as less as much as $85.7 \%$, and the mother's knowledge enough category only $14.3 \%$. The attitude of pregnant women is categorized as positive in $79.9 \%$ of pregnant women, while attitudes negative categories as much as $29.1 \%$. Actions of pregnant women get in the unfavorable category and action as much as $49.2 \%$ mom both categories as much as $50.8 \%$. Need to conduct education and community based training to build knowledge and experience of pregnant women about the risk factors of maternal death, danger signs of pregnancy, the importance of antenatal care (ANC), planning a pregnancy and a safe delivery and post natal care (PNC) as an awareness efforts against mother 
pregnant of the importance of healthy childbirth.

\section{REFERENCES}

1. WHO. Trends in maternal mortality: 1990 to 2010. WHO-World Bank UNICEF; 2012.

2. UNICEF. Maternal and Child Health, Issue Brief; Oktober. 2012.

3. Say L et al. Global Causes of Maternal Death: A Systematic Analysis WHO. Lancet. 2014;2(6):323-333.

4. Thaddeus S, M. D. Too Far To Walk: Maternal Mortality In Context. Soc Sci Med. 1994;38(1):1091-1110.

5. A James Mc Carthy and Deborah Maine. A Framework for Analyzing the Determinants of Maternal Mortality. Studies in Family Planning. 1992;23(1):23-33.

6. Vivi Yulaswati. Rough Roads Reduce Maternal Mortality. International NGO Forum on Indonesian Development (INFID); 2013.

7. Sul Sel Health Department. Health Profile of South Sulawesi, South Sulawesi Provincial Health Office, Makassar; 2013.

8. Ansariadi. Epidemiology of Maternal Mortality In South Sulawesi 20082013, What Has Changed?. Department of Epidemiology FKM UNHAS; 2014.

9. Department Health Of Jeneponto. Health Profile Jeneponto. DHO Jeneponto; 2014.

10. A.M. Okour, e. a. Maternal Mortality in Jourdan: Role of Substandard Care and Delays. Eastern Mediterranean Health Journal. 2012;18(5):426-431.

11. Yusriani. Survei Of Nutritional Status and Health Behavior of Pregnat Women. Health Journal. 2012;2(1):31-40.
12. Notoatmodjo, S. Public Health Sciences. Jakarta: PT Rineka Cipta; 2007.

13. Rukmana, S. Relationships Nutritional Intake and Nutritional Status Pregnancy Trimester III With Birth Weight Babies in Health Center Tell; 2013.

14. RISKESDAS. Basic Health Research, Balitbangkes Ministry of Health; 2013.

15. Endeavor. Mapping Mortality Patterns With Social Determinant of Health Approach In Gowa in South Sulawesi Province. Dissertation. Study Program in Medical Science. Graduate Program, University of Hasanuddin, Makassar; 2014.

16. D Waterstone M., B. S., C. Wolfe. Incidence And Predictors Of Severe Obstetric Morbidity: A Case Control Study. British Medical Journal. 2001;322(1):1089-1094.

17. Budiman. Knowledge Pregnant Women In rural Kertajaya Tanggeung District of Cianjur Regency; 2014.

18. Jokhio, A. H., Winter, Heather R. \& Cheng, Kar Keung. An Intervention Involving Traditional Birth Attendants and the Perinatal and Maternal Mortality in Pakistan. The New England Journal of Medicine. 2005;352(20):2091-2100.

19. Kruske, S. B., Lesly. Effect of Shifting Policies on Traditional Birth Attendant Training. The American College of Nurse-Midwives. 2004;49(4):306-311.

20. Miguel A Perez Raffy R Luquis. Cultural Competencein Health Education and Health Promotion, Jossey-Bass A Wiley Imprint 989 Market Street, San Francisco, CA 94103-1741-www.josseybass.com; 2008 . 
21. Ikram and Ranti, Y.F. Relationship of Knowledge and Attitudes toward Behavior Visits Pregnancy Pregnancy Examination. Sociologie Journal. 2013;1(3):204-205.

22. Dewik. et al. Health Worker Knowledge Overview of Antenatal Care in Puskesmas Ranomuut Manado City. E-Biomedical Journals (EBM). 2013;1(2):1075-1076.
23. Misar, Y. et al. Risk Factors on Maternal Maternity Complications in North Gorontalo District; 2012.

Cite this article as: Yusriani. Survey of Nutritional Status and Health Behavior of Pregnant Women in Bontomate'ne Health Center of Jeneponto District, Indonesia. Public Health of Indonesia 2016; 2(2): 5567 